\title{
Geleneksel Ev İsot Baharatının Aflatoksin İçeriğinin Belirlenmesi Üzerine Bir Araştırma
}

\author{
A. Ferit ATASOY ${ }^{1, *}$, ibrahim HAYOĞLU ${ }^{1}$, Aziz KORKMAZ ${ }^{1}$, Esra KARA ${ }^{1}$, Ali YILDIRIM ${ }^{1}$ \\ ${ }^{1}$ Harran Üniversitesi, Ziraat Fakültesi, Gıda Mühendisliği Bölümü, Şanlıurfa \\ *Sorumlu yazar: fatasoy@harran.edu.tr
}

Öz

Geleneksel yöntemle evlerde üretilen isot biberlerinin aflatoksin (AF) içeriklerini belirlemek için yapılan bu çalışmada, toplam 20 adet ev isot örneği incelenmiştir. Isot baharatlarının toplam aflatoksin içeriklerinin en az $0.02 \mathrm{ppb}$, en fazla $9.54 \mathrm{ppb}$ ve ortalama $1.52 \mathrm{ppb}$ olduğu tespit edilmiştir. 20 isot örneğinden hiçbirinde aflatoksin $G_{1} v e G_{2}$ varlığı tespit edilmemiştir. Analiz edilen örneklerden 6 tanesinde 0.02 ile $1.09 \mathrm{ppb}$ arasında $\mathrm{AFB}_{2}$ saptanmıştır. Isot örneklerinin $\mathrm{AFB}_{1}$ içeriğinin ise 0.02 ile $8.45 \mathrm{ppb}$ aralığında değiştiği belirlenmiştir. Kuru pul isot örneklerinin \%10'unun AFB 1 açısından standartlara uymadığı tespit edilmiştir. Analiz edilen örneklerin hiç birisinin toplam AF açısından yasal limitleri aşmadığı belirlenmiş̧ir.

Anahtar kelimeler: Ev isotu, Aflatoksin $\mathrm{B}_{1}$, Aflatoksin $\mathrm{B}_{2}$, Aflatoksin $\mathrm{G}_{1}$, Aflatoksin $\mathrm{G}_{2}$

\section{A Research on The Determination of Aflatoxin Content of Traditional Home Made Isot}

\begin{abstract}
In this study, 20 different home made isot samples were analyzed in order to determine the contents of aflatoxin (AF). Minumum and maximum total aflatoxin content of isots were found as $0.02 \mathrm{ppb}$ and 9.54 ppb, respectively. $A F G_{1}$ and $A F G_{2}$ did not determined in the samples. $A F B_{2}$ and $A F B_{1}$ content of isot samples ranged between 0.02-1.09 ppb and 0.02-8.45 ppb, respectively. $10 \%$ of the samples did not obey the $\mathrm{AFB}_{1}$ limit declared by TS. However, total aflatoxin content of isot did not exceed the limits.
\end{abstract}

Kew Words: Home made isot, Aflatoxin $\mathrm{B}_{1}$, Aflatoxin $\mathrm{B}_{2}$, Aflatoxin $\mathrm{G}_{1}$, Aflatoxin $\mathrm{G}_{2}$

\section{Giriş}

Kırmızıbiber (Capsicum annum L.) gıdalara kazandırdığı çeşni ve renk nedeniyle dünyada kültür yetiştiriciliği ve tüketimi domatesten sonra gelen ikinci sebzedir (Vengaiah ve Pandey, 2007). Türkiye, kırmızıbiber (Capsicum annum L.) yetiştiriciliğinde Dünyada Çin ve Meksika'dan sonra üçüncü sıradadır (Anonymous, 2013). Türkiye'de üretilen toplam yaş kırmızıbiberin \%78'lik kısmı GAP bölgesinde bulunan iller tarafından yetiştirilmektedir. Ayrıca, ülkemizde üretilen toplam yaş kırmızıbiberin yarısına yakını Şanlıurfa il sınırlarında yetiştirilmektedir (Anonim, 2015). Bu sebzeyi, bölge için kritik bir ürün haline getiren temel nedenlerin başında, bir baharat olan geleneksel isot biberi gelmektedir.

Aflatoksinler (AF), özellikle Aspergillus türü küfler (Aspergillus flavus, Aspergillus parasiticus ve Aspergillus nomius) tarafından üretilen toksik etkili bileşiklerdir. A. flavus bütün dünyada daha yaygın olarak bulunur. Küflerin aflatoksin üretimleri genetik potansiyeli, çevre koşulları (sıcaklık, pH, 
redoks potansiyeli, substrat) ve fungusla subtratın bulaşması gibi faktörlere bağı̆ıdır. Aspergillus'lar mezofilik karakterli olup 6-8 ${ }^{\circ} C^{\prime}$ den $\quad 50-60 \quad{ }^{\circ} C^{\prime}$ ye kadar gelişebilirler. Optimum gelişme sıcaklıkları $35-38^{\circ} \mathrm{C}$ dir. $10-$ $13{ }^{\circ} \mathrm{C}^{\prime}$ lerin altında ve $41-42{ }^{\circ} \mathrm{C}^{\prime}$ lerin üzerinde aflatoksin oluşumu sınırlanır. En yüksek toksin oluşumuna ise 25-30 ${ }^{\circ} C^{\prime}$ lerde ulaşır. Uluslararası Kanser Araştırma Ajansı'na (International Agency of Research on Cancer, IARC) göre aflatoksinler, birinci grup kanserojenler olarak sınıflandırılmıştır. Ultraviyole ışık altında mavi floresans verenler $A F B_{1}$ ve $A F B_{2}$, yeşil floresans verenler ise $A F G_{1}$ ve $A F G_{2}$ olarak adlandırılmaktadır. Benzer yapılara sahip toksinler olmakla birlikte başlıca aflatoksinler $\mathrm{AFB}_{1}, \mathrm{AFB}_{2}, \mathrm{AFG}_{1}$, $A F G_{2}, A F M_{1}$ ve $A F M_{2}{ }^{\prime}$ dir. Baharat çeşitleri ve diğer gıdalarda aflatoksinlerin $B_{1}, B_{2}, G_{1}$ ve $G_{2}$ formları yaygın bulunmakta ve bunlar içerisinde en toksik olanı $\mathrm{AFB}_{1}{ }^{\prime}$ dir (Ardic ve ark., 2008).

Kırımızıbiber duyusal öneminden ötürü, eskiden beri hem taze halde hem de baharat olarak tüketilse de günümüzde daha çok baharat haline getirilerek kullanılmaktadır. Günümüzde, baharatlık biber üretiminde endüstriyel metotlar yaygın olarak kullanılmakla beraber, bazı ülkelerde hala geleneksel olarak güneşte doğal şartlar altında kurutma ile biber baharatı elde edilmektedir. $\mathrm{Bu}$ ürünlerden biride Şanlıurfa'da üretilen isot baharatıdır. Önceki dönemlerde bölge insanı tarafından sadece kendi özel tüketimi için elde edilen isot biberi, günümüzde özellikle kadınlar başta olmak üzere ekonomik seviyesi düşük olan aile grupları için önemli bir gelir kaynağı olarak görülmeye başlanmıştır. Tüketicilerin de daha doğal özelliğe sahip geleneksel ürünlere eğilim göstermeye başlaması, Şanlıurfa isot biberine ulusal ve/veya uluslararası piyasada da pazarlanan bir ürün haline gelebilme imkânı sunmuştur. Ancak, bunun bir sonucu olarak, tüketiciyi yanıltmaya yönelik sadece görünüş olarak benzer özellikte olup duyusal ve hijyen kalitesi düşük ürünler de üretilmeye başlanmıştır. isotlarda gıda güvenliği açısından en önemli sorunu aflatoksin problemi oluşturmaktadır. Bu nedenle bu çalışmanın amacı evlerde geleneksel yöntemle üretilen isotların aflatoksin içeriklerini belirlemek, baharat standardı ile karşılaştırmak ve gıda güvenliği açısından değerlendirmektir.

\section{Materyal ve Metot}

Bu çalışmanın materyalini 2015 yılında evlerde geleneksel yöntemlerle üretilen 20 adet isot baharatı oluşturmaktadır.

\section{Aflatoksin Analizi}

Aflatoksin analizi, AOAC Official Method 999.07 (Anonymous, 2000) yöntemine göre HPLC sistemi ile yapılmıştır. Bu analizdeki işlemler genel olarak ekstraksiyon, temizleme ve HPLC'ye enjeksiyon aşamalarından oluşmuştur.

\section{Ekstraksiyon ve Temizleme}

500 ml'lik blender kabına (Waring 8011; Torrington, CT, U.S.A) 50 g numune tartıldıktan sonra üzerine $5 \mathrm{~g} \mathrm{NaCl}$ ilave edilmiş ve \% $80^{\prime}$ lik $300 \mathrm{ml}$ metanol eklenmiştir. Daha sonra, 5 dakika yüksek devirde karıştırılıp cam huni kullanılarak kaba filtre kâğıdından ve Whatman No: 4 filtre kâğıdından geçirilerek süzülmüştür. Süzüntüden $10 \mathrm{ml}$ pipetle alınmış ve üzerine $60 \mathrm{ml}$ fosfat tamponlu tuz çözeltisi (phospate buffered saline solution, PBS) ilave edilerek immunoaffinite safhasına geçilmiştir.

$\mathrm{Bu}$ işlem, aflatoksinler $\left(B_{1}, B_{2}, G_{1}\right.$ ve $\left.G_{2}\right)$ için özel antikor içeren bir immuno-affinite kolonu (Romerlabs, Aflastar ${ }^{\mathrm{TM}}$ FIT, Tulln, Austria) yardımıyla ekstraktın temizlenmesi 
ilkesine dayanmaktadır. Kolon sıcaklı̆ı oda şartlarına getirildikten sonra, $10 \mathrm{ml}$ ekstrakt alınarak 2-3 $\mathrm{ml}^{\text {dakika }}{ }^{-1}$ hızda olacak şekilde yerçekimi yardımıyla kolondan geçirilmiştir. Akış hızının $5 \mathrm{ml}$ dakika ${ }^{-1} y ı$ geçmemesine dikkat edilmiştir. Sonrasında, kolondan $15 \mathrm{ml}$ saf su geçirilerek yıkama işlemi yapılmış ve 10 $s$ süre ile kolondan hava geçirilerek kurutulmuştur. Aflatoksinlerin ayrışması için $0.5 \mathrm{ml}$ metanol kolondan yerçekimi yardımıyla yavaşça geçirilerek $3 \mathrm{ml}$ 'lik balon jojeye alınmıştır. Bir dakika bekledikten sonra, ikinci kez olarak $0.75 \mathrm{ml}$ metanol kolondan geçirilip hava yardımıyla pozitif basınç oluşturularak ayrıştırmada kullanılan metanolün tamamen balon jojeye alınması sağlanmıştır. Saf su ile hacim 3 ml'ye tamamlanmış ve bir vorteks ile iyice karıştırıldıktan sonra $1 \mathrm{ml}$ 'lik viale alınarak HPLC'ye enjeksiyon yapılmıştır. Kullanılan çözücü ve kimyasalların HPLC Grade kalitesinde olmasına dikkat edilmiştir.

\section{HPLC Koşulları ve Miktar Tayini}

Aflatoksinlerin HPLC (SHIMADZU LC-20AD Prominence, Shimadzu Corp, Kyoto, Japonya) sistemi ile kantitatif analizinde FLD (RF10AXL) detektörü ile çalışılmıştır. Bazı aflatoksinleri ( $B_{1}$ ve $G_{1}$ ) detektörde tespit edebilmek amacıyla da HPLC ve detektör arasına türevlendirme hücresi (Kobra Cell) eklenmiş ve brominasyon ile elektrokimyasal olarak türevlendirme yapılmıştır. Afltoksinlerin FLD detektörde tespiti $360 \mathrm{~nm}$ (excitaiton) ve $430 \mathrm{~nm}$ (emission) dalga boyu aralığında yapılmıştır. Ayrıştırma için mobil faz olarak, saf su:Asetonitril:metanol (6:2:3/v:v:v) karışımı kullanılmış ve akış hızı 1 $\mathrm{ml}$ dakika $^{-1}$ olarak ayarlanmıştır. Mobil faz karışımının 1 litresinde 120 potasyum bromid ( $\mathrm{KBr}$, Sigma-Aldrich) ve $350 \mu \mathrm{l}$ nitrik asit (4 M) çözeltisi ilave edilmiştir. Mobil faz kullanılmadan önce $0.45 \mu \mathrm{m}$ gözenekli PTFE filtreden geçirilmiştir. Akış hızı $1 \mathrm{ml}$ /dakika, fırın sıcaklığı $40{ }^{\circ} \mathrm{C}$ ve kolon basıncı $<180$ bar olarak ayarlanmıştır. Her bir örnek için iki defa olacak şekilde $100 \mu$ l kadar ekstrakt HPLC'ye enjekte edilmiştir.

Miktar tayininde Aflatoksin standartları olarak $B_{1}, B_{2}, G_{1}$ ve $G_{2}$ aflatoksinlerinden her birini $250 \mathrm{ng} \mathrm{ml}^{-1}$ oranında içeren ticari

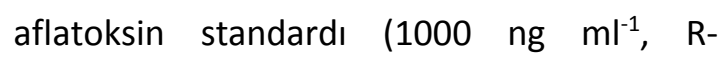
Biopharm, Darmstadt, Almanya) kullanılmıştır. Metanol ile her bir aflatoksini $25 \mathrm{ng} \mathrm{ml}^{-1}$ oranında içeren stok standart çözeltisi hazırlanmıştır. Bu stok çözeltiden de her bir $0.5,1.0,1.5,2.5$ ve $5 \mathrm{ng} \mathrm{ml}^{-1}$ konsantrasyonlarda çözeltiler hazırlanarak kalibrasyon eğirişi oluşturulmuştur. HPLC'ye $100 \mu$ l enjekte edilip her bir konsantrasyona karşılık elde edilen pikin elektronik alanı belirlenerek 5 noktalı kalibrasyon eğrileri elde edilmiştir. Doğrusal regresyon ile örneklerin aflatoksin içerikleri hesaplanmıştır ve sonuçlar ppb $\left(\mu \mathrm{g} \mathrm{kg}^{-1}\right)$ olarak ifade edilmiştir.

\section{Araştırma Bulguları ve Tartışma}

Aflatoksinlerin LOD, LOQ ve geri kazanım değerleri Çizelge 1'de gösterilmiştir. Analiz edilen isot örneklerin aflatoksin içerikleri Çizelge 2'de verilmiştir.

Örneklerin 1 tanesinin hiç aflatoksin içermediği tespit edilmemiştir. Evlerde üretilen 20 isot örneğinin hiçbirisinde $A F G_{1}$ ve $\mathrm{AFG}_{2}$ varlığı tespit edilmemiştir. Analiz edilen örneklerden 6 tanesinde $\mathrm{AFB}_{2}$ saptanmış olup bunların miktarlarının 0.02 ile 1.09 ppb arasında olduğu belirlenmiştir. isot örneklerinin $\mathrm{AFB}_{1}$ içeriğinin 0.02 ile 8.45 ppb aralığında değiştiği saptanmıştır. isot baharatlarının toplam aflatoksin içeriklerinin en az 0.02 ppb, en fazla 9.54 ppb ve ortalama $1.52 \mathrm{ppb}$ olduğu tespit edilmiştir. Ardıç ve ark. (2008) 75 isot örneği üzerinde aflatoksin içeriğinin varlığını araştırdıkları çalışmalarında 72 örneğin $A F B_{1}$ içerdiğini ve miktarlarının 
0.11 ile 24.7 ppb arasında değiştiğini saptamışlardır. İnce tabaka kromotografisi ile 20 isot numunesinde aflatoksin araması yapılan bir araştırmada, sadece 1 örnekde aflatoksin $(B+G)$ belirlenmiş olup değerinin $13.8 \mathrm{ppb}$ olduğu bildirilmektedir (Erdoğan, 2004).

Çizelge 1. Uygulanan Aflatoksin Analiz Metoduna Ait Performans Göstergeleri

Table 1. The Performance Value of The Aflatoxin Analyses Method

\begin{tabular}{|c|c|c|c|}
\hline Çeşit (Type) & LOD $^{\mathbf{a}}(p p b)$ & LOQ $^{\mathbf{b}}(p p b)$ & Geri Kazanım (Recovery) (\%) \\
\hline $\mathrm{AFG}_{2}$ & 0.062 & 0.210 & 82.06 \\
\hline $\mathrm{AFG}_{1}$ & 0.180 & 0.600 & 92.72 \\
\hline $\mathrm{AFB}_{1}$ & 0.158 & 0.530 & 93.59 \\
\hline $\mathrm{AFB}_{2}$ & 0.054 & 0.180 & 82.63 \\
\hline
\end{tabular}

a Tespit Limiti (Limit of Detection, LOD)

${ }^{\mathrm{b}}$ Tayin Limiti (Limit of Quantification, LOQ)

Çizelge 2. Analiz Edilen Örneklerin Aflatoksin İçerikleri (ppb)

Table 2. Aflatoxin Content of The Samples (ppb)

\begin{tabular}{|c|c|c|c|c|c|}
\hline $\begin{array}{l}\text { Örnek } \\
\text { Samples }\end{array}$ & $\mathrm{AFG}_{2}$ & $\mathrm{AFG}_{1}$ & $\mathrm{AFB}_{2}$ & $\mathrm{AFB}_{1}$ & $\begin{array}{c}\text { Toplam AF } \\
\text { Total AF }\end{array}$ \\
\hline 1 & -1 & -1 & -1 & 0.05 & 0.05 \\
\hline 2 & - & - & - & 0.42 & 0.42 \\
\hline 3 & - & - & - & 0.05 & 0.05 \\
\hline 4 & - & - & - & 0.03 & 0.03 \\
\hline 5 & - & - & - & 0.11 & 0.11 \\
\hline 6 & - & - & - & 0.02 & 0.02 \\
\hline 7 & - & - & 0.02 & 1.28 & 1.30 \\
\hline 8 & - & - & 1.09 & 8.45 & 9.54 \\
\hline 9 & - & - & - & 0.33 & 0.33 \\
\hline 10 & - & - & 0.16 & 6.72 & 6.88 \\
\hline 11 & - & - & - & -1 & -1 \\
\hline 12 & - & - & 0.22 & 2.35 & 2.57 \\
\hline 13 & - & - & - & 0.02 & 0.02 \\
\hline 14 & - & - & - & 0.33 & 0.33 \\
\hline 15 & - & - & - & 0.22 & 0.22 \\
\hline 16 & - & - & - & 0.52 & 0.52 \\
\hline 17 & - & - & 0.18 & 2.95 & 3.13 \\
\hline 18 & - & - & - & 0.72 & 0.72 \\
\hline 19 & - & - & 0.29 & 3.35 & 3.64 \\
\hline 20 & - & - & - & 0.57 & 0.57 \\
\hline En az & - & - & 0.02 & 0.02 & 0.02 \\
\hline En fazla & - & - & 1.09 & 8.45 & 9.54 \\
\hline Ortalama & - & - & 0.10 & 1.42 & 1.52 \\
\hline
\end{tabular}

${ }^{1}$ Tespit edilemedi veya LOQ değerinin altındadır.

Genel olarak isotların aflatoksin içeriklerinin çok düşük olmasına rağmen, bazı örneklerin yüksek içeriğe sahip olmasının kullanılan taze biber çeşit ve kalitesinden, üretim yeri ve şeklinden kaynaklandığı tahmin edilmektedir. Yine, üretim zamanlarının farklı olması ve süresinin ailelere göre değişmesi bu farklılıkların oluşmasında etkili olduğu düşünülmektedir. Kontrollü şartlarda üretilen kuru pul isot baharatında aflatoksin içeriklerin 
çok düşük olduğu belirtilmektedir (Atasoy ve ark. 2016).

Aflatoksin $B_{1}$ ve toplam aflatoksin için izin verilen değerin Türk Gıda Kodeksi Bulaşanlar Yönetmeliği (TGK, 2011) ve Avrupa Birliği gıda mevzuatında (EU, no 165/2010) 5 ppb ve 10 $\mathrm{ppb}$ olduğu bildirilmektedir (Anonymous, 2010; Anonim, 2011). Kuru pul isot örneklerinin \%10'unun (8 ve 10 nolu örnek) $\mathrm{AFB}_{1}$ açısından standartlara uymadığı tespit edilmiştir. Analiz edilen örneklerin hiç birisinin toplam AF açısından yasal limitleri aşmadığı belirlenmiştir. 75 isot örneği üzerinde yapılan bir çalışmada örneklerin \%14.7'sinin $\mathrm{AFB}_{1}$ açısından standartlara uymadığı belirtilmektedir (Ardıç ve ark. 2008).

İsot baharatı üretiminde kullanılan taze biberlerin su aktivitesinin yüksek ve isotun karakteristik rengi için uzun kurutma süresi uygulanmasına rağmen, kurutma sırasında su aktivitesinin hızlı bir şekilde düşmesi nedeniyle aflatoksin gelişimini sınırlandırıldığı belirtilmektedir. Ayrıca, üretim sırasında kullanılan beton zeminin güneşten dolayı biberlerin sıcaklığını yükseltmesi ve böylece kurutma işleminin daha etkin ve hızlı gerçekleşmesinin de su aktivitesinin hızlı düşmesinde ve aflatoksin gelişimini engellemede etkili olduğu bildirilmektedir (Atasoy ve ark. 2016). Kurutma sırasında biber baharatlarında oluşan aflatoksin miktarı, kurutulan biberin çeşidi ve su aktivitesi (Marin ve ark., 2009), kurutma sıcaklığı ve iklim koşulları (Cho ve ark., 2008) gibi faktörlere bağlı olarak değişebilmektedir. Aflatoksin oluşumunda kurutma süresinin de önemli bir etken olduğu ve bu sürenin uzamasına bağıı olarak aflatoksin oluşumunun da arttığı belirtilmektedir (Inan ve ark., 2007).

\section{Sonuçlar}

Baharatlarda gıda güvenliği açısından en önemli sorunu aflatoksin problemi oluşturmaktadır. Aflatoksinler, tarımsal ürünlerin kurutulması sırasında uygun rutubet içeriğine bağlı olarak ürünlerde oluşabilmektedir. Nitekim analiz edilen isotlardan \%10'unun $\mathrm{AFB}_{1}$ açsından yasal limitlerin üstünde değer içerdiği saptanmıştır. Ancak belli kurallara dikkat edildiğinde Şanlıurfa'da yaygın olarak üretilen ve sevilerek tüketilen isotlarda gıda güvenliğini sağlamak mümkündür. Bu nedenle "güvenilir ev isotu" üretebilmek için;

- Hasatı ve taşınması sırasında, kurutulması süresince biberlerin zedelenmesini neden olacak hareketlerden kaçınılmalıdır.

- Taze biberler büyük yığınlar halinde ve çuvallar içerisinde uzun süre bekletilmemelidir.

- Üretime başlamadan önce, zedelenmiş, parçalanmış özellikle de çürümüş taze biberlerin uzaklaştırılması gerekmektedir.

- Biberler mümkün olduğunca küçük parçalara ayrılmalı ve ince serim yapılmalıdır.

- Biberlerin kurutulması sırasında toprakla temas kesinlikle engellenmeli, olabildiğince temiz ortamlarda (mesela damlarda), temiz bir bez üzerinde kurutulmalıdır.

- Kullanılan malzemelerin, özellikle polietilen torbaların, temiz, kuru ve zarar görmemiş olması gerekmektedir.

\section{Kaynaklar}

Anonim, 2011. Türk Gıda Kodeksi (TGK) Bulaşanlar Yönetmeliği, T.C. Resmi Gazete, 28157(3), 29 Aralık 2011.

Anonim,

2015. https://biruni.tuik.gov.tr/bitkiselapp/bitkis el.zul. Erişim tarihi: 10.09.2016.

Anonymous, 2000. Aflatoxin $B_{1}$ and Total Aflatoxins in Peanut Butter, Pistachio Paste, Fig Paste, and Paprika Powder. AOAC Official Method 999.07.

Anonymous, 2010. Commission Regulation (EU) No 165/2010, Amending Regulation (EC) No 1881/2006 Setting Maximum Levels for 
Certain Contaminants In Foodstuffs as Regards Aflatoxins. Official Journal of The European Union, 53, 27.02.2010

Anonymous, 2013. http://faostat3.fao.org/ download /Q/QC/E. Erişim tarihi: 29.10.2016.

Ardic, M., Karakaya, Y., Atasever, M., Durmaz, H., 2008. Determination of Aflatoxin B1 Levels in Deep-red Ground Pepper (isot) Using Immunoaffinity Column Combined with ELISA. Food and Chemical Toxicology, 46:1596-1599.

Atasoy, A. F., Aydoğdu, M. H., Korkmaz, A., Kara, E., 2016. Urfa İsot Biberinin Özelliklerinin Belirlenerek Pazar Potansiyelinin Artırılması. Kalkınma bakanlığı GAP Bölge Kalkınma idaresi Başkanlığı, Tarımsal Araştırma Destekleri Proje Sonuç Raporu, 270 s.

Cho, S-H., Lee, C-H., Jang, M-R., Son, Y-W., Lee, SM., Choi, I-S., Kim, S-H., Kim, D-B., 2008. Aflatoxins Contamination in Spices and Processed Spice Products Commercialized in Korea. Food Chemistry, 107:1283-1288.

Erdoğan, A., 2004. The aflatoxin contamination of some pepper types sold in Turkey. Chemosphere, 56: 321-325.

Inan, F., Pala, M., Doymaz, I., 2007. Use of Ozone in Detoxification of Aflatoxin B1 in Red Pepper. Journal of Stored Products Research, 43: 425-429.

Marin, S., Colom, C., Sanchis, V., Ramos, A., J., 2009. Modelling of Growth of Aflatoxigenic A. Flavus Isolates from Red Chilli Powder as a Function of Water Availability. International Journal of Food Microbiology, 128: 491-496.

Vengaiah, P. C., Pandey, J. P., 2007. Dehydration Kinetics of Bell pepper (Capsicum annum L.). Journal of Food Engineering, 81: 282286. 